PRODUÇÃO ANIMAL

\title{
COMPORTAMENTO INGESTIVO DE VACAS EM LACTAÇÃO EM PASTAGEM CONSORCIADA NO PERÍODO ESTIVAL
}

\section{INGESTIVE BEHAVIOR OF DAIRY COWS GRAZING INTERCROPPED PASTURES IN WARM SEASON}

\author{
Magnos Fernando Ziech ${ }^{1 *}$ \\ Clair Jorge Olivo \\ Gilmar Roberto Meinerz ${ }^{3}$ \\ Carlos Alberto Agnolin² \\ Fernando Skonieski ${ }^{4}$
}

1 Universidade Tecnológica Federal do Paraná, Dois Vizinhos, PR, Brasil.

2Universidade Federal de Santa Maria, Santa Maria, RS, Brasil

${ }^{3}$ Universidade Federal Fronteira Sul, Cerro Largo, RS, Brasil

${ }^{4}$ Universidade Federal Fronteira Sul, Realeza, PR, Brasil

*Autor para correspondência - magnos@utfpr.edu.br

\section{Resumo}

A pesquisa teve como objetivo estudar o comportamento ingestivo de vacas da raça Holandesa em lactação, durante o período estival, em pastagens constituídas por capim-elefante (Pennisetum purpureum Schum.) e espécies de crescimento espontâneo, consorciadas com trevo branco (Trifolium repens L.) ou amendoim forrageiro (Arachis pintoi Krap. \& Greg.). Foram feitas avaliações em três pastejos (dezembro, fevereiro e abril). Para cada avaliação utilizaram-se seis vacas entre o segundo e o quinto mês de lactação. O registro de dados foi realizado das 18 às 06 horas e das 08 às 16 horas, a cada 10 minutos. Os parâmetros comportamentais observados foram o tempo de pastejo em capimelefante, pastejo das espécies estabelecidas na entrelinha, pastejo total (pastejo do capim-elefante e da forragem na entrelinha), ruminação e ócio. O tempo médio de pastejo da entrelinha foi de $3 \mathrm{~h} 48$ min e $2 \mathrm{~h} 9 \mathrm{~min}$ para os consórcios com o trevo branco e amendoim forrageiro, respectivamente, sendo superior $(\mathrm{P}<0,05)$ para a primeira mistura de forrageiras. $\mathrm{O}$ tempo médio de pastejo diário do capim elefante foi de 5 h 32 min e 6 h 27 min, para os respectivos consórcios, não havendo diferença entre eles. Para os tempos de ruminação e ócio houve similaridade entre as pastagens estudadas.

Palavras-chave: capim-elefante; etologia; pastejo rotacionado; valor nutritivo

\begin{abstract}
This research aimed to study the behavior of Holstein lactating cows, during the warm-season on a pasture constituted by elephant grass (Pennisetum purpureum Schum.) and spontaneous growing species intercropped with white clover (Trifolium repens L.) or forage peanut (Arachis pintoi Krap $\&$ Greg.). Evaluations were taken during three grazing in December, February, and April. Six cows between the second and fifth lactation month were used for each evaluation. The data were recorded at a 10 min-interval, from 6 P.M. to 6 A.M. and from 8 A.M. to 4 P.M. The grazing time on elephant grass, on species established in space between lines, total grazing (elephant grass and species established in space between lines), rumination and idleness were the behavioral parameters observed. The average of grazing was $3 \mathrm{~h} 48 \mathrm{~min}$ and $2 \mathrm{~h} 9$ min for pastures intercropped with white clover and forage peanut, respectively, being higher $(\mathrm{P}<0.05)$ for the first intercropped forage. The average of the grazing on elephantgrass was $5 \mathrm{~h} 32 \mathrm{~min}$ and $6 \mathrm{~h} 27 \mathrm{~min}$ for the respective intercropped pastures systems, with
\end{abstract}


no statistical difference between them. The rumination and idleness were similar among the pastures. Keywords: elephant grass; ethology; nutritive value; rotational grazing.

Enviado em: 25 setembro 2013

Aceito em: 22 dezembro 2015

\section{Introdução}

O sistema de criação de bovinos baseado no pasto caracteriza-se por uma série de fatores que afetam o comportamento ingestivo dos animais, comprometendo o seu desempenho ${ }^{(1)}$. Em condições de pastejo, os bovinos leiteiros apresentam comportamento típico com picos de alimentação ao amanhecer e anoitecer ${ }^{(2)}$, podendo ser modificados de acordo com o tipo, a quantidade, a acessibilidade ao alimento e as práticas de manejo ${ }^{(3)}$. A quantidade de matéria seca e, principalmente, a disponibilidade de folhas verdes acessíveis nos horizontes superficiais da pastagem afetam o tempo de permanência dos ruminantes na busca e colheita de alimento ${ }^{(4)}$. A facilidade de apreensão da forragem é outro fator que determina o aumento ou a redução no tempo de pastejo, alterando, consequentemente, os tempos de ruminação e ócio ${ }^{(5)}$.

Para avaliar forrageiras sob pastejo, além da simples comparação do desempenho obtido, é necessário mensurar as diferenças entre as espécies avaliadas ${ }^{(6)}$, pois elas podem afetar os hábitos alimentares dos bovinos. Normalmente, as espécies tropicais em comparação às temperadas tornam-se fibrosas mais rapidamente (com redução da qualidade), havendo limitação no consumo de forragem. Conforme Carvalho et al. ${ }^{(7)}$, o entendimento dos fatores que restringem o consumo de pastagens tropicais é de grande importância para utilização eficiente das pastagens. Características de estrutura do dossel indicam aos animais as possíveis condições para a seleção de forragem ${ }^{(6)}$. O conhecimento do comportamento ingestivo dos bovinos leiteiros pode ser utilizado pelos produtores, de forma que venha a maximizar a produtividade, garantindo também melhor saúde e, consequentemente, maior longevidade aos animais ${ }^{(8)}$.

Em pastagens de ciclo estival, constituídas por consórcios forrageiros, envolvendo capim elefante e diferentes leguminosas, estima-se que ocorra grande variabilidade, tanto nas composições botânica (do pasto) e estrutural (das plantas), quanto no valor nutricional da forragem. Há também comportamento ingestivo distinto em diferentes épocas do período estival. Esses resultados podem proporcionar orientação para melhoria no manejo dos pastos, auxiliando na preservação das espécies perenes e também no manejo dos animais, visando à melhoria da dieta, do consumo e da produção de leite. Considerando estes aspectos e a escassez de estudos sobre o comportamento ingestivo de vacas em lactação em consórcios forrageiros, o objetivo desta pesquisa foi estudar, durante o período estival, o comportamento de vacas lactantes, em pastagens constituídas por capim-elefante, espécies de crescimento espontâneo e trevo branco ou amendoim forrageiro, avaliando-se o tempo de pastejo nas espécies predominantes, a ruminação e o ócio.

\section{Material e Métodos}

O trabalho foi conduzido no Laboratório de Bovinocultura de Leite, pertencente ao Departamento de Zootecnia da UFSM, situado na região da Depressão Central (Santa Maria - RS) a 29 43' de latitude Sul e $53^{\circ} 42^{\prime}$ de longitude Oeste, com clima subtropical úmido ${ }^{(9)}$. A precipitação anual varia de 1.300 a $1.800 \mathrm{~mm}$ e a temperatura média é de $19,2^{\circ} \mathrm{C}$. O solo é classificado como Argissolo Vermelho distrófico arênico ${ }^{(10)}$. A área utilizada $(1,0 \mathrm{ha})$ foi dividida em quatro piquetes $(0,25 \mathrm{ha})$, de modo que o capim-elefante (Pennisetum purpureum Schum.), cv. Merckeron pinda, constituiu a base do sistema forrageiro. O capim-elefante foi estabelecido em linhas afastadas a cada $4 \mathrm{~m}$; nas entrelinhas, o amendoim forrageiro (Arachis pintoi Krap. \& Greg.), cv. Amarillo, foi implantado em metade da área (dois piquetes) com densidade de semeadura de $12 \mathrm{~kg} / \mathrm{ha}$. Em meados de abril 
fez-se a semeadura do azevém (40 kg/ha) mediante escarificação do solo; na outra metade da área experimental, durante a estação fria, mediante escarificação do solo, foram estabelecidos o trevobranco (Trifolium repens L.), cv. Yi, em densidade de $4 \mathrm{~kg} / \mathrm{ha}$ e o azevém (40 kg/ha). Durante todo o período de avaliação na pastagem, de junho a abril, permitiu-se o desenvolvimento de espécies de crescimento espontâneo. Para adubação, foram utilizados $40 \mathrm{~kg} /$ ha de fósforo e de potássio, conforme análise de solo e recomendação para as leguminosas usadas ${ }^{(11)}$. No período, realizou-se adubação nitrogenada na forma de ureia, na proporção de $50 \mathrm{~kg} / \mathrm{ha}$ ano, divididos em duas aplicações.

Os tratamentos foram constituídos por dois sistemas forrageiros, sendo um com capim-elefante + trevo branco + espécies de crescimento espontâneo; e outro com capim-elefante + amendoim forrageiro + espécies de crescimento espontâneo. As observações de cada sistema forrageiro foram realizadas em três pastejos, conduzidos em dezembro de 2005, fevereiro e abril de 2006. Em cada avaliação, utilizaram-se seis vacas da raça Holandesa entre o segundo e o quinto mês de lactação, com aproximadamente $500 \mathrm{~kg}$ de peso corporal e produção média diária de $15 \mathrm{~kg}$ de leite, recebendo complementação alimentar de $3,5 \mathrm{~kg}$ de concentrado com $20 \%$ de PB, fracionado e fornecido duas vezes ao dia, após as ordenhas (manhã e tarde). As vacas foram mantidas nas pastagens das 8 às $16 \mathrm{~h}$ e das 18 às 6 h, com sombra, água e sal mineral à disposição.

Avaliaram-se os tempos de pastejo (no alinhamento formado pelas touceiras de capim-elefante e nas entrelinhas), a ruminação e o ócio. As observações foram realizadas em turnos de quatro horas, sendo feitas concomitantemente por dois avaliadores a cada 10 minutos, nas 20 horas diárias. As vacas eram retiradas da pastagem duas vezes ao dia para as ordenhas da manhã e tarde, quando também recebiam a complementação alimentar, perfazendo o período de quatro horas no qual as atividades não eram registradas.

O critério de utilização da pastagem teve como base o capim-elefante, quando essa forrageira apresentava aproximadamente $120 \mathrm{~cm}$ de altura. Para se determinar a carga animal, procurou-se manter a oferta de forragem entre 8 e $10 \mathrm{~kg}$ para a forragem presente nas entrelinhas e $4 \mathrm{~kg}$ de MS por $100 \mathrm{~kg}$ de peso vivo para a biomassa de lâminas foliares verdes de capim-elefante (nas linhas), com base na massa de forragem inicial da pastagem, estimada mediante técnica com dupla amostragem ${ }^{(12)}$, efetuando-se 20 estimativas visuais e cinco cortes, nas entrelinhas (rente ao solo) e nas linhas (cortes a $50 \mathrm{~cm}$ do solo). Nos cálculos, estimou-se em $25 \%$ a área ocupada pelo capim-elefante (linha) e $75 \%$ pela forragem presente nas entrelinhas.

Para se determinar o valor nutritivo, foram retiradas, em cada avaliação (pastejo), amostras de simulação da pastagem $^{(13)} \mathrm{e}$, isoladamente, do capim-elefante (CE) e da entrelinha, no momento da entrada e da saída dos animais. As amostras foram secadas, moídas e posteriormente analisadas para a determinação do teor de PB, pelo método de Kjeldahl, FDN ${ }^{(14)}$, DIVMS e DIVMO ${ }^{(15)}$.

O delineamento experimental foi inteiramente casualizado com dois tratamentos (sistemas forrageiros) e seis repetições (vacas). Para análise dos dados, utilizou-se o procedimento MIXED ${ }^{(16)}$, considerando um modelo misto. O modelo analítico incluiu o efeito dos tratamentos e dos períodos de pastejo, juntamente com as respectivas interações. A matriz de variância e co-variância usada foi de estrutura heterogênea de primeira ordem auto-regressiva ARH (1).

O modelo estatístico foi representado por Yijk $=\mu+\mathrm{Ti}+\mathrm{Rj}+\mathrm{Rj}(\mathrm{Ti})+\mathrm{Pk}+\mathrm{TiPk}+$ eijk; em que Yijk se refere às variáveis dependentes; $\mu$ é a média de todas as observações; Ti é o efeito dos sistemas forrageiros; $\mathrm{Rj}$ é o efeito das repetições (vacas); $\mathrm{Rj}(\mathrm{Ti})$ é o efeito da j-ésima repetição dentro do i-ésimo sistema forrageiro (erro A); Pk é o k-ésimo efeito dos pastejos; TiPk é a interação sistema forrageiro $\times$ pastejo; e cijk é o erro experimental residual (erro B).

\section{Resultados e Discussão}

Para os resultados referentes aos tempos de pastejo das vacas entre o alinhamento formado pelas touceiras de capim-elefante, houve diferença $(\mathrm{P}<0,05)$ entre os sistemas forrageiros, com valor superior no consórcio com o trevo branco (Tabela 1). 
Tabela 1: Dados comportamentais (\%) de vacas em lactação, em 20h diárias, manejadas em sistemas forrageiros constituídos por capim-elefante, espécies de crescimento espontâneo e trevo branco (1) ou amendoim forrageiro (2), Santa Maria, RS

\begin{tabular}{ccccccc}
\hline \multicolumn{7}{c}{ Pastejos } \\
\hline Variáveis & $\begin{array}{c}\text { Sistema } \\
\text { Forrageiro }\end{array}$ & Dezembro & Fevereiro & Abril & Média & CV (\%) \\
\hline PE & 1 & $16,61 \mathrm{aA}$ & $12,57 \mathrm{aA}$ & $16,39 \mathrm{aA}$ & $15,86 \mathrm{a}$ & 34,99 \\
& 2 & $10,15 \mathrm{bA}$ & $8,75 \mathrm{bA}$ & $8,06 \mathrm{bA}$ & $8,99 \mathrm{~b}$ & \\
PC & 1 & $25,18 \mathrm{bA}$ & $30,74 \mathrm{aA}$ & $27,19 \mathrm{aA}$ & 27,7 & 18,94 \\
& 2 & $38,61 \mathrm{aA}$ & $25,82 \mathrm{aB}$ & $32,37 \mathrm{aAB}$ & 32,27 & \\
PT & 1 & $43,79 \mathrm{aA}$ & $43,30 \mathrm{aA}$ & $43,58 \mathrm{aA}$ & 43,56 & 10,28 \\
& 2 & $48,76 \mathrm{aA}$ & $34,56 \mathrm{aB}$ & $40,40 \mathrm{aB}$ & 41,25 & \\
R & 1 & $39,14 \mathrm{aA}$ & $36,47 \mathrm{aA}$ & $35,66 \mathrm{aA}$ & 37,09 & 10,77 \\
& 2 & $38,59 \mathrm{aA}$ & $38,66 \mathrm{aA}$ & $38,52 \mathrm{aA}$ & 38,59 & \\
& 1 & $17,07 \mathrm{aA}$ & $20,22 \mathrm{aA}$ & $20,76 \mathrm{aA}$ & 19,35 & 27,74 \\
& 2 & $12,64 \mathrm{aB}$ & $26,77 \mathrm{aA}$ & $21,04 \mathrm{aA}$ & 20,15 & \\
\hline
\end{tabular}

Médias seguidas por letras maiúsculas distintas, na linha, diferem entre si ( $\mathrm{P}<0,05)$.

Médias seguidas por letras minúsculas distintas nas colunas, diferem entre si $(\mathrm{P}<0,05)$.

PE - tempo de pastejo da entrelinha; PC - tempo de pastejo do capim-elefante, PT- tempo de pastejo total;

R - ruminação; O - ócio.

Na primeira avaliação, efetuada em dezembro, o maior tempo disponibilizado pelos animais se deve à elevada participação do trevo branco na composição do pasto (Tabela 2), que, como espécie de ciclo hibernal, é normalmente preferida pelos animais em relação às de ciclo estival. Este resultado foi confirmado pela taxa de desaparecimento de matéria seca na entrelinha nesse período, que foi de $1,86 \%$ onde havia a presença do trevo em relação à do amendoim forrageiro, de 1,06\% (Tabela 2). Esse comportamento também está associado ao melhor valor nutritivo do pasto presente na entrelinha no consórcio com trevo branco, com maiores teores de proteína bruta e digestibilidade e menor de fibra em detergente neutro (Tabela 3). Nos demais pastejos, no consórcio com trevo, houve predominância de espécies de crescimento espontâneo (Tabela 2), especialmente por papuã (Urochloa plantaginea), milhã (Digitaria sanguinalis) e Paspalum conjugatum, verificando-se maior tempo de consumo, indicando que os animais demandaram mais tempo selecionando a dieta com essas espécies do que aquela composta por essas espécies e amendoim forrageiro. Entre os pastejos, dentro de cada sistema forrageiro, não houve diferença para o tempo de pastejo, indicando que houve regularidade no tempo de consumo entre as épocas avaliadas. Os valores da taxa de desaparecimento da forragem (Tabela 2) confirmam essa assertiva.

Quanto ao pastejo do capim-elefante, maior tempo $(\mathrm{P}<0,05)$ foi disponibilizado pelas vacas no consórcio com amendoim forrageiro, compensando, assim, o menor tempo disponibilizado na entrelinha que, além de apresentar forragem menos palatável, tinha em sua composição elevada participação de material morto (Tabela 2), composto basicamente por material remanescente do azevém em final de ciclo e do amendoim forrageiro, devido à ação cumulativa do frio e das geadas. Esse resultado é confirmado também pela elevada taxa de desaparecimento de forragem verificada para o capimelefante, de $2,85 \%$, se comparada com o valor verificado no consórcio com trevo branco, de $1,76 \%$ (Tabela 2). Nas demais avaliações efetuadas em fevereiro e abril não houve diferença no tempo de pastejo do capim-elefante. Esse resultado, em parte, está associado à similaridade nas variáveis de valor nutritivo do capim-elefante (Tabela 3). Entre pastejos não houve diferença no consórcio com o trevo branco; no sistema com amendoim forrageiro, o menor tempo de pastejo do capimelefante é atribuído, em parte, à menor participação de lâminas foliares dessa forrageira (Tabela 2), possivelmente devido ao maior tempo de pastejo disponibilizado pelas vacas no pastejo anterior. 
Tabela 2: Massa de forragem (MF) de pré e pós-pastejo dos componentes e taxa de desaparecimento (TD) das pastagens nos diferentes sistemas forrageiros (SF), constituídos por capim-elefante (CE), espécies de crescimento espontâneo $(\mathrm{ECE})$ e trevo branco (SF1) ou amendoim forrageiro (SF2), Santa Maria, RS

\begin{tabular}{|c|c|c|c|c|}
\hline & SF & Dezembro & Fevereiro & Abril \\
\hline \multirow{2}{*}{$\begin{array}{l}\text { MF de pré-pastejo de CE } \\
\text { (ton/ha de MS) }\end{array}$} & 1 & 2,27 & 3,20 & 3,00 \\
\hline & 2 & 3,40 & 4,16 & 4,03 \\
\hline \multirow{2}{*}{ - Lâmina foliar (\%) } & 1 & 43,61 & 43,13 & 21,33 \\
\hline & 2 & 39,71 & 33,17 & 22,33 \\
\hline \multirow{2}{*}{ - Colmo + bainha $(\%)$} & 1 & 48,02 & 49,06 & 62,00 \\
\hline & 2 & 50,88 & 57,45 & 59,80 \\
\hline \multirow{2}{*}{ - Material morto (\%) } & 1 & 8,37 & 7,81 & 16,33 \\
\hline & 2 & 9,41 & 9,13 & 17,87 \\
\hline \multirow{2}{*}{$\begin{array}{l}\text { MF de pré-pastejo na } \\
\text { entrelinha (ton/ha de MS) }\end{array}$} & 1 & 1,90 & 1,10 & 1,17 \\
\hline & 2 & 1,03 & 1,70 & 1,26 \\
\hline \multirow{2}{*}{ - Leguminosa (\%) } & 1 & 61,28 & 1,02 & 0,0 \\
\hline & 2 & 10,23 & 27,42 & 28,88 \\
\hline \multirow{2}{*}{ - Outras espécies (\%) } & 1 & 17,81 & 93,11 & 91,89 \\
\hline & 2 & 34,63 & 60,98 & 57,83 \\
\hline \multirow{2}{*}{ - Material morto (\%) } & 1 & 20,81 & 5,89 & 8,19 \\
\hline & 2 & 55,16 & 11,60 & 15,66 \\
\hline \multirow{2}{*}{$\begin{array}{l}\text { MF de pós-pastejo de CE } \\
\text { (ton/ha de MS) }\end{array}$} & 1 & 1,6 & 2,0 & 2,4 \\
\hline & 2 & 2,7 & 2,8 & 3,0 \\
\hline \multirow{2}{*}{ - Lâmina foliar (\%) } & 1 & 16,58 & 16,11 & 12,37 \\
\hline & 2 & 19,96 & 14,78 & 11,06 \\
\hline \multirow{2}{*}{ - Colmo + bainha (\%) } & 1 & 73,52 & 67,29 & 68,78 \\
\hline & 2 & 65,85 & 68,08 & 64,47 \\
\hline \multirow{2}{*}{ - Material morto (\%) } & 1 & 9,91 & 16,60 & 18,84 \\
\hline & 2 & 14,19 & 17,14 & 24,46 \\
\hline \multirow{2}{*}{$\begin{array}{l}\text { MF de pós-pastejo na } \\
\text { entrelinha (ton/ha de MS) }\end{array}$} & 1 & 1,21 & 0,63 & 0,84 \\
\hline & 2 & 0,80 & 1,17 & 0,87 \\
\hline \multirow{2}{*}{ - Leguminosa $(\%)$} & 1 & 47,46 & 1,11 & 0,0 \\
\hline & 2 & 5,95 & 22,98 & 29,31 \\
\hline \multirow{3}{*}{ - Outras espécies (\%) } & 1 & 27,94 & 84,41 & 76,24 \\
\hline & 2 & 24,34 & 63,15 & 57,00 \\
\hline & 1 & 24,60 & 14,48 & 23,76 \\
\hline - Material morto $(\%)$ & 2 & 69,72 & 13,87 & 13,68 \\
\hline \multirow{2}{*}{ - TD Total $(\%)$} & 1 & 3,63 & 3,22 & 3,16 \\
\hline & 2 & 3,91 & 3,26 & 3,51 \\
\hline \multirow{2}{*}{ - TD do CE (\%) } & 1 & 1,76 & 2,30 & 2,00 \\
\hline & 2 & 2,85 & 2,33 & 2,55 \\
\hline \multirow{2}{*}{ - TD Entrelinha (\%) } & 1 & 1,86 & 0,91 & 1,16 \\
\hline & 2 & 1,06 & 0,93 & 0,97 \\
\hline
\end{tabular}

Para o tempo de pastejo total (linha e entrelinha), não houve diferença entre os sistemas forrageiros. Esse resultado é atribuído à oferta de forragem utilizada (4\% para biomassa de lâminas foliares de capim-elefante e $8 \%$ para a massa de forragem na entrelinha) e a disponibilidade de espécies, possibilitando, assim, condições de seleção do material forrageiro. Entre os pastejos, houve diferença $(\mathrm{P}<0,05)$ no consórcio com amendoim forrageiro, com maior valor na avaliação realizada em dezembro sobre as demais, resultado atribuído ao menor tempo disponibilizado pelas vacas no consumo da forragem presente na entrelinha.

O tempo médio de pastejo, em 20 horas diárias, de 42,40\% ( 8 h e 29 min) foi inferior ao observado 
por Olivo et al. ${ }^{(17)}$, de $9 \mathrm{~h}$ e 16 min, que estudou vacas da raça Holandesa e mesma sistemática de complementação alimentar, em pastagens de capim-elefante consorciado com aveia e azevém no período hibernal. Esse tempo também é inferior ao verificado por Olivo et al. ${ }^{(18)} \mathrm{em}$ mesma área, ao utilizar misturas forrageiras de capim-elefante, azevém e trevo branco ( $9 \mathrm{~h}$ e $36 \mathrm{~min}$ ) ou amendoim forrageiro ( $8 \mathrm{~h}$ e $55 \mathrm{~min}$ ) no período hibernal. Aurélio et al. ${ }^{(19)}$, trabalhando na estação quente com vacas da raça Holandesa, encontraram médias mais elevadas de $9 \mathrm{~h}$ e 44 min e $9 \mathrm{~h}$ e 02 min para pastejo de capim elefante anão e Tifton 85 , respectivamente, na região fisiográfica do Planalto do Rio Grande do Sul, devido à não complementação alimentar das vacas. Phillips et al. ${ }^{(20)}$, avaliando o comportamento ingestivo de vacas da mesma raça recebendo diariamente $2 \mathrm{~kg}$ de concentrado em pastejo de azevém perene, verificaram tempo médio diário de $8 \mathrm{~h}$ e $9 \mathrm{~min}$, sendo similar ao do presente trabalho.

Para o tempo de ruminação, não houve diferença tanto entre sistemas quanto entre pastejos. Esse resultado é atribuído à similaridade do valor nutritivo das forragens e a oferta utilizada, que não implicou em limitação do consumo, condição esta que pode ser constatada pelos valores de massa de forragem residual (Tabela 2), notadamente de lâmina foliar do capim-elefante.

Tabela 3: Valor nutritivo das pastagens nos diferentes sistemas forrageiros (SF), constituídos por capim-elefante (CE), espécies de crescimento espontâneo (ECE) e trevo branco (SF1) ou amendoim forrageiro (SF2), Santa Maria, RS

\begin{tabular}{lccccc}
\hline & & Dezembro & Fevereiro & Abril & Média \\
\hline Variável & SF & \multicolumn{5}{c}{$(\%)$} & \\
\hline \multirow{2}{*}{ PB do CE } & 1 & 13,31 & 12,85 & 11,97 & 12,71 \\
& 2 & 13,19 & 12,92 & 13,00 & 13,04 \\
PB na EL & 1 & $20,17 \mathrm{a}$ & 8,13 & 9,57 & 12,62 \\
& 2 & $11,63 \mathrm{~b}$ & 11,27 & 10,96 & 11,29 \\
FDN do CE & 1 & 55,74 & 54,63 & 56,26 & 55,54 \\
& 2 & 54,25 & 55,77 & 54,57 & 54,76 \\
FDN na EL & 1 & $23,05 \mathrm{~b}$ & 54,96 & 47,75 & 41,92 \\
& 2 & $50,22 \mathrm{a}$ & 53,04 & 47,38 & 50,21 \\
\multirow{2}{*}{ DIVMS do CE } & 1 & 64,83 & 67,54 & 66,31 & 66,23 \\
& 2 & 66,65 & 71,56 & 68,40 & 68,87 \\
DIVMS na EL & 1 & $89,63 \mathrm{a}$ & 68,91 & 69,68 & 76,07 \\
& 2 & $68,95 \mathrm{~b}$ & 72,68 & 66,01 & 69,21 \\
\hline
\end{tabular}

Médias seguidas por letras distintas, na coluna, para cada parâmetro, diferem entre si pelo teste $\mathrm{F}$ $(\mathrm{P}<0,05) ; \mathrm{CE}=$ capim-elefante; $\mathrm{TB}=$ trevo branco; $\mathrm{AF}=$ amendoim forrageiro; $\mathrm{ECE}=$ espécies de crescimento espontâneo.

O valor médio de ruminação de $37,84 \%$ (7h e $34 \mathrm{~min}$ ) é similar aos valores obtidos por Balocchi et al. ${ }^{(21)}$, que observaram variação entre $7 \mathrm{~h}$ e $20 \mathrm{~min}$ e $7 \mathrm{~h}$ e $30 \mathrm{~min}$, em 24 horas de observação, ao estudarem vacas em lactação, em pastagem de azevém perene e complementação diária de concentrado de $6 \mathrm{~kg}$. Esses valores também são semelhantes aos encontrados por Olivo et al. ${ }^{(22)}, 7 \mathrm{~h}$ e $43 \mathrm{~min}$ em média de três avaliações entre as estações do inverno e da primavera, utilizando manejo similar ao presente estudo, em pastagens consorciadas (capim-elefante + aveia preta) submetidas a técnicas agroecológicas.

Quanto ao tempo de ócio, não foram observadas diferenças entre sistemas. Entre as avaliações também não foram encontradas diferenças no consórcio com trevo branco. No sistema com amendoim forrageiro, o menor $(\mathrm{P}<0,05)$ tempo de ócio, verificado em dezembro, foi devido à maior necessidade de seleção da forragem, atribuída à composição do pasto com elevada participação de material morto 
e ao menor valor nutritivo do pasto na entrelinha (Tabelas 2 e 3). O tempo médio de ócio de 19,75\% ( $3 \mathrm{~h}$ e $57 \mathrm{~min}$ ) é inferior ao encontrado em estudo desenvolvido por Olivo et al. ${ }^{(17)}$, que verificaram 5 h e 8 min de ócio em 20 horas de observação, e aos encontrados por Zanine et al. ${ }^{(23)}$, estudando vacas Holandês x Zebu no terço inicial de lactação em pastejo contínuo de Brachiaria decumbens ou Brachiaria brizantha, encontrando $4 \mathrm{~h}$ e $47 \mathrm{~min}$ e $4 \mathrm{~h}$ e $59 \mathrm{~min}$ para as respectivas pastagens. Essas comparações apontam que os animais demandaram mais tempo para selecionar sua dieta, implicando em menor tempo de ócio, justificado pela mistura forrageira que apresenta picos e ciclos diferenciados de produção. Em trabalho semelhante, desenvolvido na mesma área no período hibernal, Olivo et al. ${ }^{(18)}$ observaram valores de $2 \mathrm{~h}$ e $36 \mathrm{~min}$ e $3 \mathrm{~h}$ e $24 \mathrm{~min}$, para pastagens de capim-elefante consorciada com azevém mais trevo branco e azevém mais amendoim forrageiro, respectivamente, sendo inferiores aos do presente estudo. Isso é justificado pela presença de espécies de ciclo hibernal, especialmente o azevém, que possibilitam maior taxa de passagem e consequente maior ingestão de forragem.

\section{Conclusões}

O comportamento ingestivo das vacas leiteiras é distinto entre os sistemas forrageiros, com maior tempo disponibilizado no consórcio com trevo branco na área entre os alinhamentos formados pelas touceiras do capim elefante, em função do melhor valor nutritivo dessa leguminosa em relação ao amendoim forrageiro. Considerando-se o tempo total de pastejo, verificou-se similaridade entre os sistemas forrageiros, devido à diversidade de espécies forrageiras, permitindo que os animais equilibrassem a dieta. Entre as avaliações, a presença das leguminosas implicou em menor tempo disponibilizado ao consumo. Para as demais variáveis comportamentais de ruminação e ócio, houve similaridade entre os sistemas forrageiros avaliados.

\section{Referências}

1. Pardo RMP, Fischer V, Balbinotti M et al. Comportamento ingestivo diurno de novilhos em pastejo a níveis crescentes de suplementação energética. Revista Brasileira de Zootecnia, 2003; 32(6): 1408-1418.

2. Peres Neto D, Ribeiro ARB, Rodrigues AA, Ferreira RP, Mendonça FC. et al. Diurnal behavior of dairy cows on alfalfa pastures supplemented with corn silage and concentrate. Arquivo Brasileiro de Medicina Veterinária e Zootecnia. 2014; 66(3) 837-844.

3. Fischer V, Deswysen AG, Dutilleul P, Boever J. Padrões da distribuição nictemeral do comportamento ingestivo de vacas leiteiras, ao final da lactação, alimentadas com dieta á base de silagem de milho. Revista Brasileira de Zootecnia, 2002; 31(5): 2129-2138.

4. Trevisan NB, Quadros, FLF, Silva ACF, Bandinelli DG, Martins CEM. Efeito da Estrutura de uma Pastagem Hibernal sobre o Comportamento de Pastejo de Novilhos de Corte. Revista Brasileira de Zootecnia, 2005; 34(3) 774-780.

5. Nascimento GV do, Cardoso EA, Batista NL, Souza BB, Cambuí GB. Comportamento ingestivo de vacas mestiças (holandês/zebu) sob regime de pastejo rotacionado em brachiaria brizantha cv. Marandu. Journal of Animal Behavior and Biometeorology 2013; 1(2): 31-36.

6. Costa VG, Rocha MG, Pötter L, Roso D, Rosa ATN, Reis J. Comportamento de pastejo e ingestão de forragem por novilhas de corte em pastagens de milheto e papua. Revista Brasileira de Zootecnia, 2011; 40(2): 251-259.

7. Carvalho PCF, Kozloski GV, Ribeiro Filho HMN, Reffatti MV, Genro TCM, Euclides VPB. Avanços metodológicos na determinação do consumo de ruminantes em pastejo. Revista Brasileira de Zootecnia, 2007; 36(Suplemento especial): 151-170.

8. Silva RR, Prado IN, Carvalho GGP, Oliveira AP, Almeida VVS; Souza DR, Santana Junior HA, Silva FF. Efeito da presença do bezerro sobre o comportamento ingestivo de vacas leiteiras em pastejo de Brachiaria 
decumbens. Revista Brasileira de Saúde e Produção Animal. 2007; 8(1): 48-55.

9. Alvares C A, Stape JL, Sentelhas PC, Gonçalves JLM, Sparovek G. Köppen's climate classification map for Brazil. Meteorologische Zeitschrift, 2014; 22 (6): 711-728.

10. EMBRAPA - Empresa Brasileira de Pesquisa Agropecuária. Centro Nacional de Pesquisa de Solos. Sistema brasileiro de classificação de solos. Embrapa Produção de Informação, Brasília, 3 ed., 2013. 353p, Portuguese.

11. COMISSÃO DE QUÍMICA E FERTILIDADE DO SOLO - RS/SC. Manual de adubação e calagem para os Estados do Rio Grande do Sul e de Santa Catarina. Porto Alegre, 10. ed. SBCS-CQFS, 2004; 400 p. Portuguese. Disponível em http://www.sbcs-nrs.org.br/docs/manual de adubacao_2004 versao internet.pdf, acesso em dezembro 2015.

12. Wilm HG, Costelo OF, Klipple GE. Estimating forage yield by the double sampling method. Journal American Society of Agronomy, 1944; 36: 194-203.

13. Euclides VPB, Macedo MCM, Oliveira MP. Avaliação de diferentes métodos de amostragem para estimar o valor nutritivo de forragens sob pastejo. Revista Brasileira de Zootecnia, 1992; 21(4): 691-702.

14. Van Soest PJ, Robertson JB, E Lewis BA Methods for Dietary Fiber, Neutral Detergent Fiber, and Nonstarch Polysaccharides in Relation to Animal Nutrition. Journal of Dairy Science, 1991; 74(10): 35833597.

15. Tilley JMA, Terry RA. A two-stage technique of the "in vitro" digestion of forage crop. Journal of the British Grassland Society, 1963; 18(2): 104-111.

16. SAS INSTITUTE, Statistical Analysis System: User's guide [CD-ROM], Version 6.11, Cary (NC): Sas Institute, Inc., 2001.

17. Olivo CJ, Charão PS, Ziech MF, Rossarolla G, Moraes RS. Comportamento de Vacas em Lactação em Pastagem Manejada sob Princípios Agroecológicos. Revista Brasileira de Zootecnia, 2006; 35(6): 24432450.

18. Olivo CJ, Ziech MF, Meinerz GR, Both JF, Agnolin CA, Vendrame T. Comportamento ingestivo de vacas em lactação em diferentes sistemas forrageiros. Revista Brasileira de Zootecnia. 2008; 37(11): 2017-2023.

19. Aurélio ND, Quadros FLF, Maixner AR, Rossi GE, Daniel E, Roman J, Bandinelli DG, Trindade JJP, Brum MS. Comportamento ingestivo de vacas holandesas em lactação em pastagens de capim-elefante anão (Pennisetum purpureum cv. Mott) e Tifton 85 (Cynodon dactylon x C. nlemfuensis) na região noroeste do Estado do Rio Grande do Sul. Ciência Rural, 2007; 37(2): 470-475.

20. Phillips CJ, Rind MI. The effects of social dominance on the production and behavior of grazing dairy cows offered forage supplements. Journal of Dairy Science, 2001; 85(1): 51-59.

21. Balocchi O, Pulido R, Fernández J. Comportamiento de vacas lecheras en pastoreo com y sin suplementación com concentrado. Agricultura Técnica, 2002; 62(1): 87-98.

22. Olivo CJ, Sobczak MF, Charão PS, Heimerdinger A, Silva JHS. Comportamento de vacas em lactação em pastagem manejada sob princípios agroecológicos. Ciência Rural, 2005; 35(4): 862-869.

23. Zanine AM, Santos EM, Parente HN, Ferreira DJ, Cecon PR. Hábito de pastejo de vacas lactantes Holandês x Zebu em pastagens de Brachiaria brizantha e Brachiaria decumbens. Arquivo Brasileiro de Medicina Veterinária e Zootecnia. 2007; 59(1): 175-181. 